\title{
O coordenador pedagógico nos sistemas de ensino do Rio de Janeiro: uma nova aposta na gestão das escolas?
}

\author{
The pedagogical coordinator in the educational systems of Rio de Janeiro: a \\ new bet on school management? \\ El coordinador pedagógico en los sistemas de enseñanza de Rio de Janeiro: \\ ¿una nueva apuesta en la gestión de las escuelas?
}

SABRINA MOEHLECKE

Resumo: Neste artigo, pretende-se identificar a complexidade dos desafios da gestão escolar nos sistemas de ensino do Rio de Janeiro e o lugar do coordenador pedagógico enquanto figura de mediação na gestão das escolas. Realiza-se uma revisão da literatura sobre coordenação pedagógica para identificar as principais questões em debate. Em seguida, são analisados os dados dos municípios e do Estado do Rio de Janeiro para dimensionar a complexidade da gestão escolar. Por fim, para mensurar a relevância do coordenador pedagógico, são levantados os editais de concurso público para a função. Dentre os resultados, observou-se um crescimento na demanda por coordenadores pedagógicos no Rio de Janeiro, com uma mudança em seu perfil e qualificação, indicando um fortalecimento de seu lugar na gestão escolar.

Palavras-chave: políticas públicas; gestão escolar; coordenação pedagógica.

Abstract: In this article, we intend to identify the complexity of the challenges of school management in the educational systems of Rio de Janeiro and the place of the pedagogical coordinator as a figure of mediation in the management of schools. We carry out a literature review on pedagogical coordination to identify the main issues under discussion. Next, we analyze the data of the municipalities and the State of Rio de Janeiro to measure the complexity of school management. Finally, in order to measure the relevance of the pedagogical coordinator, we raise the public tender notices for the function. Among the results, there is an increase in the demand for pedagogical coordinators in Rio de Janeiro, with a change in their profile and qualification, which indicates a strengthening of their place in school management.

Keywords: Public policies; school management; pedagogical coordination.

Resumen: En ese artículo se pretende identificar la complejidad de los retos de la gestión escolar en los sistemas de enseñanza de Rio de Janeiro y el lugar del coordinador pedagógico como figura de mediación en la gestión de las escuelas. Se realiza una revisión de la literatura sobre coordinación pedagógica para identificar las principales cuestiones en debate. A continuación, son analizados los datos de los municipios y del Estado de Rio de Janeiro para dimensionar 
la complejidad de la gestión escolar. Por fin, para mensurar la relevancia del coordinador pedagógico, son observadas las llamadas de concurso público para la función. Entre los resultados, se observó un crecimiento en la demanda por coordinadores pedagógicos en Rio de Janeiro, con un cambio en su perfil y calificación, indicando un fortalecimiento de su lugar en la gestión escolar.

Palabras clave: Políticas públicas; gestión escolar; coordinación pedagógica.

\section{INTRODUÇÃO}

No contexto educacional brasileiro, a questão da qualidade do ensino tem sido tema predominante no debate da área nos últimos vinte anos (OLIVEIRA e ARAÚJO, 2005; ALBERNAZ, FERREIRA e FRANCO, 2002; OLIVEIRA, 2007; ALVEZ, BONAMINO e FRANCO 2007). Esse é o pano de fundo que justifica os vários sistemas de avaliação criados desde então, seja em âmbito nacional, seja nos estados e municípios. As políticas e programas formulados para responder aos resultados dos diagnósticos apresentados por tais sistemas de avaliação foram muitas, especialmente se considerarmos os diferentes níveis administrativos. Contudo, pode-se identificar uma preocupação cada vez mais direcionada e focada no nível das escolas e, dentro destas, no plano de sua gestão.

O modo como as escolas na Educação Básica organizam seu trabalho é apontado por diversos estudos (SOARES e ANDRADE, 2006; FRANCO et al. 2007; BROOKE e SOARES, 2008; BONAMINO e LIMA, 2013) como ponto central para a melhoria da aprendizagem dos alunos e seu consequente 'sucesso escolar'. Nessa direção, por exemplo, seguem as pesquisas sobre o 'clima escolar', ao ressaltar aspectos como, por exemplo, o grau de satisfação e comprometimento em relação à escola; os modos de interação entre os membros; as formas de liderança do diretor; valores, atitudes e comportamentos; reações às normas e códigos de conduta, por exercerem forte influência na aprendizagem dos alunos (BLANCO, 2008).

No âmbito do Ministério da Educação, inserem-se dentro desse escopo de políticas voltadas para a dinâmica de gestão da escola Programas como o PNEGEB (Programa Nacional de Educação e Gestão na Educação Básica), que atua na formação de diretores e coordenadores pedagógicos das escolas, o Programa Nacional de Fortalecimento do Conselho Escolar, entendido como relevante instância de gestão democrática nas escolas, entre outros. No Estado do Rio de Janeiro, tais programas federais, em convênio com o governo estadual e alguns municípios, estão em vigência desde 2008, colocando em prática o regime de colaboração entre os entes federados.

Observam-se ainda várias ações em âmbito local (estadual e municipal) que privilegiam essa mesma preocupação, com políticas e programas direcionados 
às escolas e a suas instâncias de gestão. São exemplo disso o curso para diretor escolar criado pela Prefeitura do Rio de Janeiro, exigência para aqueles que irão ocupar tal cargo e, também, os vários concursos abertos para coordenador pedagógico em diversos municípios do Estado.

A maioria dos estudos atuais sobre as políticas educacionais direcionadas ao nível da gestão escolar têm focado suas análises, geralmente baseadas em pesquisa documental, na explicitação das concepções de gestão que informam tais políticas e programas, onde identificam uma tensão entre a noção de gestão democrática, como preconizada pela Constituição Federal de 1988 e pela Lei de Diretrizes e Bases da Educação Nacional de 1996, e uma concepção de cunho mais gerencialista, que retomaria princípios e orientações da administração mais tradicional, conceituada por alguns autores como "neo-taylorismo" (LIMA, 2003).

Contudo, no campo da análise das políticas públicas, tem sido identificada a necessidade, cada vez mais premente, de se observarem não apenas o processo de formulação de políticas no âmbito do poder central, mas também sua implantação nas esferas mais locais, pois nem sempre aquilo que é concebido por seus formuladores é executado exatamente conforme o planejado. No nível meso das organizações, tem-se observado que seus agentes, com relativos graus de autonomia, reapropriam e ressignificam as orientações advindas da esfera central (MELO, 1999; SOUZA, 2003).

Neste artigo, que apresenta os primeiros resultados de uma pesquisa mais ampla sobre a implementação de políticas públicas no nível da gestão escolar, pretende-se identificar a complexidade dos desafios dessa gestão presentes nos sistemas de ensino públicos de municípios e do Estado do Rio de Janeiro e o lugar ocupado, hoje, pelo coordenador pedagógico enquanto figura de mediação dessa gestão no interior das escolas.

Desse modo, realiza-se inicialmente uma breve revisão da literatura sobre coordenação pedagógica no Brasil, de maneira a identificar as principais questões em debate acerca do tema. Em seguida, são compilados e organizados dados estatísticos dos municípios e do Estado do Rio de Janeiro e de suas redes de ensino, de forma a dimensionar alguns dos desafios que interferem na complexidade da gestão escolar. Por fim, como estratégia para mensurar a relevância atual do coordenador pedagógico nas redes de ensino dos municípios e do Estado, são levantados os editais de concurso público para o exercício dessa função nas escolas. 


\section{COORDENAÇÃO PEDAGÓGICA NAS ESCOLAS: UMA BREVE REVISÃO DA LITERATURA}

Adentrar essa área implica deparar-se com grande variedade de expressões e nomenclaturas utilizadas ao longo da história da educação no Brasil para designar diferentes funções criadas para a ação junto à gestão das escolas. A própria LDBEN/96 utiliza os termos inspeção, supervisão e orientação educacional para se referir ao profissional da educação que atua nas funções de orientação e coordenação pedagógicas, expressões que também ganham contornos locais nas legislações de estados e municípios. Desse modo, neste levantamento privilegiamse os estudos recentes que se debruçam sobre esse profissional que tem uma ação junto aos docentes e a suas práticas pedagógicas nas escolas, independente de usarem ou não o termo coordenador pedagógico.

Historicamente, essa função remonta a experiências educacionais da década de 20, com os primeiros registros legais nacionais na década de 30. No contexto da Reforma Francisco Campos, por meio dos Decretos-Lei no. 19.890/31 e no. 21.241/32, foi criada a função de inspetor escolar, que deveria atuar no controle e fiscalização das normas prescritas pelos órgãos centrais superiores junto às escolas de ensino secundário e às práticas pedagógicas dos seus professores. Essa função era exercida por professores considerados bem sucedidos e com ampla experiência educacional (ROMANELLI, 2011). Nessa época, vigorava uma concepção de escola pretensamente neutra, baseada na hierarquização de funções e tarefas, com um currículo único, centralizado e homogeneizador de competências e hábitos que destituía o professor de sua capacidade reflexiva e criativa, dentro de uma dicotomia do fazer pedagógico.

$\mathrm{Na}$ década de 70, com o recrudescimento dessa concepção tecnicista da educação, foi criada a função de supervisor pedagógico, por meio do $1^{\circ}$ Estatuto do Magistério, de 1974, tendo sido suas atribuições definidas nos DecretosLei no 5586/75 e no7510/76, intensificando a divisão do trabalho pedagógico. Enfatizaram-se ainda mais a separação entre concepção/planejamento e execução, entre as funções dos gestores escolares e o trabalho dos professores em sala de aula. Cabia aos especialistas em educação definir metodologias e apostilas didáticas, sem discussão ou consulta aos docentes, além de fiscalizar sua aplicação em sala de aula. Nesse momento, o supervisor pedagógico estava fortemente associado à fragmentação do trabalho escolar, dentro de uma rígida hierarquia de poder dentro da escola (LIBÂNEO, 2005).

Ainda que algumas experiências educacionais nos anos 60 tenham tensionado esse modelo de gestão, mesmo que de forma pontual, como os ginásios vocacionais e as escolas experimentais (FUSARI, 1997; TAMBERLINI, 
2001), foi somente no contexto de redemocratização do país nos anos 1980 que a função de coordenador pedagógico ganhou maior abrangência, dentro de relações de poder mais horizontais e descentralizadas. Um novo perfil de profissional começa a ocupar esse espaço, com distintas funções dentro de uma proposta de gestão democrática das relações intra e extra escolares, conforme preconizado pela Constituição Federal de 1988 e pela Lei de Diretrizes e Bases da Educação de 1996, apesar de suas limitações regulatórias (PARO, 2007; ADRIÃO, 2007). Nesse momento, o coordenador pedagógico ganha o papel de articulador e formador, voltado ao trabalho de ensino-aprendizagem junto aos docentes e aos processos de gestão, dentro de uma proposta de construção pela escola, de forma coletiva e participativa, de seu projeto político e pedagógico, envolvendo professores, alunos, pais, funcionários, comunidade. As expectativas quanto a sua atuação envolvem a superação da antiga divisão do trabalho escolar e a dicotomia entre pensar/planejar e fazer/executar (ALMEIDA;PLACCO, 2001).

Contudo, na grande maioria das pesquisas recentes sobre o lugar do coordenador pedagógico na gestão da escola, é recorrente a constatação de uma ambiguidade em sua identidade, bem como na definição de seu papel e espaços de atuação (GUIMARÃES et al., 2008; BRUNO; ALMEIDA; CRISTOV, 2000; ALMEIDA; PLACCO, 2001). Na prática, suas funções têm oscilado entre a articulação e coordenação, de modo colaborativo, do conjunto do trabalho coletivo desenvolvido na escola e a supervisão e controle, de modo técnico e burocrático, do trabalho docente. $\mathrm{O}$ coordenador pedagógico às vezes continua atuando, ainda que nem sempre de forma explícita, como fiscal da secretaria municipal de educação nas escolas, com a função de gerir a escola em sintonia com as diretrizes da secretaria. Em outras, pode ser uma figura chave para garantir uma autonomia relativa da escola e da produção docente de modo a construir e executar efetivamente seu projeto político pedagógico de modo participativo (FERREIRA; AGUIAR, 2002; OLIVEIRA, 2009).

O que se percebe é que seus papéis ainda variam consideravelmente entre os sistemas de ensino, principalmente de acordo com suas concepções de gestão educacional. Nesse sentido, três questões foram identificadas como as mais recorrentes e relevantes na literatura sobre o tema: a) a necessidade ou não de uma formação específica para o exercício da atividade de coordenador pedagógico; b) a forma de ingresso na função; c) a definição de atribuições mais pedagógicas ou mais burocráticas.

Com relação à sua qualificação, é necessário que o coordenador pedagógico seja formado em Pedagogia ou qualquer professor, com alguma experiência 
no magistério, poderia exercer essa função? Deve ele ser um especialista, com formação específica em gestão, ou apenas uma formação geral em licenciatura é suficiente?

Em Minas Gerais, por exemplo, nas escolas particulares, o coordenador pedagógico é um pedagogo que ocupa um cargo de confiança do diretor. Nas escolas municipais, ele é um professor, denominado "professor coordenador pedagógico" (PCP), muitas vezes eleito pelos seus pares. Já na cidade de Belo Horizonte, pedagogos não são mais contratados como especialistas desde 1992 (cf. SANTOS; OLIVEIRA, 2007).

Em São Paulo, nos anos 80, foi criada a função de professor coordenador pedagógico no intuito de auxiliar o governo na implantação da política de Ciclo Básico e do Projeto Noturno nas escolas da rede estadual, sendo ele eleito, anualmente, pelos professores e referendado pelo Conselho da Escola (FERNANDES, 2009). Já nos anos 90, no bojo das reformas educacionais do período, foi expandida essa função para todas as escolas públicas estaduais paulistas com mais de dez classes em funcionamento (Idem). A partir de 2006, qualquer professor com mais de três anos de magistério, independentemente de sua formação inicial, poderia ocupar a função de Professor Coordenador. Sem a necessidade de uma formação em Pedagogia nem habilitação na área, o ingresso na função não exige um especialista da educação nem mesmo larga experiência profissional na docência.

No Rio de Janeiro, para atender à formação docente dos CIEPs, foram instituídos em 1983 os professores orientadores (POs). Oriundos do quadro docente estadual e municipal, eles deveriam dar apoio permanente aos professores por meio de cursos de formação em serviço. Contudo, até 2011, a função de coordenador pedagógico não estava regulamentada no sistema estadual do Rio de Janeiro e os diretores é que escolhiam, de maneira informal, algum professor para exercer a função (Idem).

De modo geral, o conjunto dos estudos analisados, elaborados pari passo a um processo de redefinição e institucionalização da função de coordenador pedagógico nos sistemas de ensino nos anos 80 e 90, identificam e propõem como principal atribuição dos CPs a 'educação continuada' dos professores nas escolas (CHRISTOV, 2008; GUIMARÃES et. al., 2008; PLACCO; ALMEIDA; SOUZA, 2011). Vista como atribuição essencial do coordenador pedagógico e associada ao processo de formação em serviço dos professores, a educação continuada é composta por "diferentes ações como cursos, congressos, seminários, HTPC (horário de trabalho pedagógico coletivo), orientações técnicas, estudos individuais" e vem associada a uma crítica aos termos "treinamento, capacitação, reciclagem, que não privilegiam a construção da autonomia intelectual do professor, uma vez 
que se baseiam em propostas previamente elaboradas a serem apresentadas aos professores para que as implantassem em sala de aula." (CHRISTOV, 2008, p. $9-10)$.

No entanto, um dado importante trazido pelas pesquisas empíricas desenvolvidas com coordenadores pedagógicos é que, apesar das normativas e orientações formais que definem seus papéis, o exercício de sua função, na prática, está muito distante do proposto, influenciada principalmente pelas necessidades imediatas que surgem na escola e no âmbito dos sistemas de ensino. Muitas vezes, ele acaba sendo um "faz tudo", sem tempo para exercer, de forma sistemática, quer a função de fiscalização, quer a de articulador e formador coletivo (TORRES, 2003; PLACCO; ALMEIDA; SOUZA, 2011; PLACCO; ALMEIDA, 2015).

De acordo com estudos na área, a não exigência de uma formação pedagógica, que permitiu a muitos professores assumirem a função de coordenação pedagógica sem terem um conhecimento de didática, currículo e gestão escolar, contribuiu para uma atuação pouco consciente de sua função profissional e tornou mais árdua ou quase inexistente a tarefa de realizar uma efetiva educação continuada com os professores (cf. CHRISTOV, 2001. FERNANDES, 2009; PLACCO, 2011).Fernandes vai além, quando associa essa fragilidade na formação a uma tendência do CP de exercer atividades mais burocráticas e a atuar de modo a veicular e defender projetos da Secretaria de Educação junto aos docentes da escola, sem uma mediação crítica, aproximando-se de uma atuação gerencial da educação (Idem)

Diante do conjunto de questões trazidas pelos estudos na área, quais mudanças podemos identificar quanto ao lugar atribuído ao coordenador pedagógico nos sistemas de ensino do Rio de Janeiro? Há hoje uma maior demanda no Estado e nos municípios pela contratação desse profissional? Com relação à sua qualificação, percebe-se uma maior exigência de formação específica na área pedagógica? Quanto às formas de ingresso na função, permanecem as tradicionais indicações ou já existem formas mais impessoais de acesso?

\section{COMPLEXIDADE DA GESTÃO DOS SISTEMAS DE ENSINO E DAS ESCOLAS}

O Estado do Rio de Janeiro, com um território de 43 milhões km2, tem uma população de 15.989.929 milhões de habitantes, distribuídos por 92 municípios (IBGE, 2010). Na capital, concentram-se 40\% da população, num total de 6.320.446 pessoas. Alguns municípios do Estado se sobressaem pela quantidade de habitantes, mas, em sua maioria, são unidades administrativas de pequeno porte, com menos de 90 mil habitantes (69\%) (gráfico 1). Desse modo, 
para observar a complexidade da gestão municipal em sua respectiva rede pública de ensino, foram selecionados para análise apenas as cidades com mais de 90 mil habitantes, o que totalizou 29 municípios.

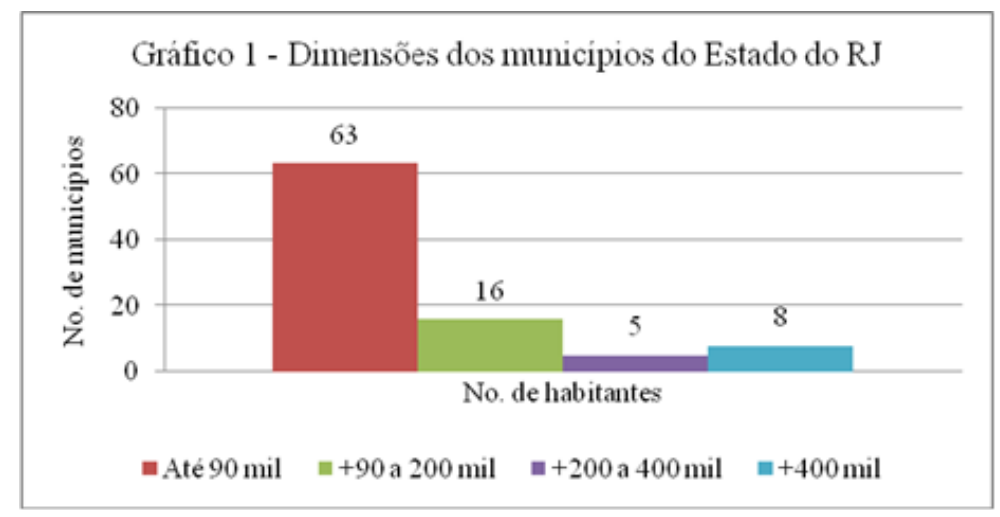

Fonte: IBGE, 2010.

Em termos da complexidade da gestão nos sistemas de ensino, particularmente no interior das escolas do Rio de Janeiro, foram levantados, nos municípios selecionados, dados estatísticos referentes ao número de escolas e ao número de matrículas de cada rede. Além disso, utilizou-se um indicador de gestão elaborado pelo INEP, que agrega o número de matrículas em cada escola do município, a quantidade de turnos em que funcionam e os níveis e as modalidades de ensino nela oferecidos. Em uma escala que vai de 1 a 6, mede-se o grau de complexidade exigido na organização interna da escola, tanto em termos administrativos quanto pedagógicos, aspectos centrais a serem observados quando da discussão sobre a relevância e as funções de coordenadores pedagógicos na gestão escolar.

Primeiramente, no que se refere ao número de escolas, o gráfico 2 mostra que, dos 29 municípios analisados, apenas oito possuem até 50 escolas municipais. Dentre os demais, 14 apresentam uma rede de ensino de 50 a 100 escolas e sete municípios administram mais de 100 escolas. Na faixa de mais de 100 a 200 escolas estão os municípios de Macaé, Nova Friburgo, Nova Iguaçu, Petrópolis e Duque de Caxias; na faixa de mais de 200 a 300 escolas está Campos de Goytacazes e na de mais de 300 escolas o Município e o Estado do Rio de Janeiro. 


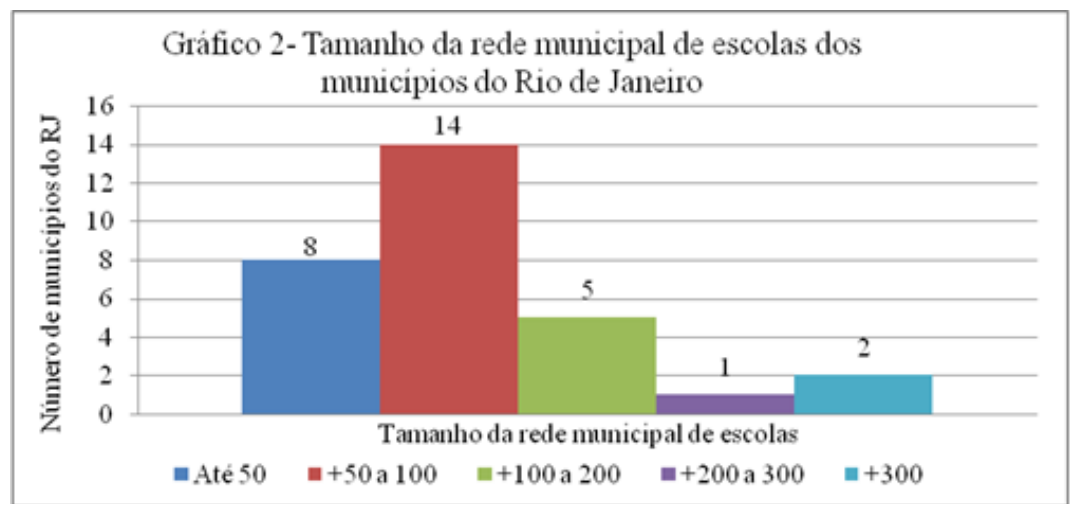

Fonte: INEPDATA-Ensino regular, 2013.

Contudo, nem todas as redes municipais com grande número de escolas trazem também alto número de matrículas, indicando que, em algumas cidades, existem muitas escolas, o que aumenta a complexidade da gestão no âmbito do município, mas grande parte delas é de pequeno porte, o que facilita sua gestão no que concerne à dinâmica interna da escola.

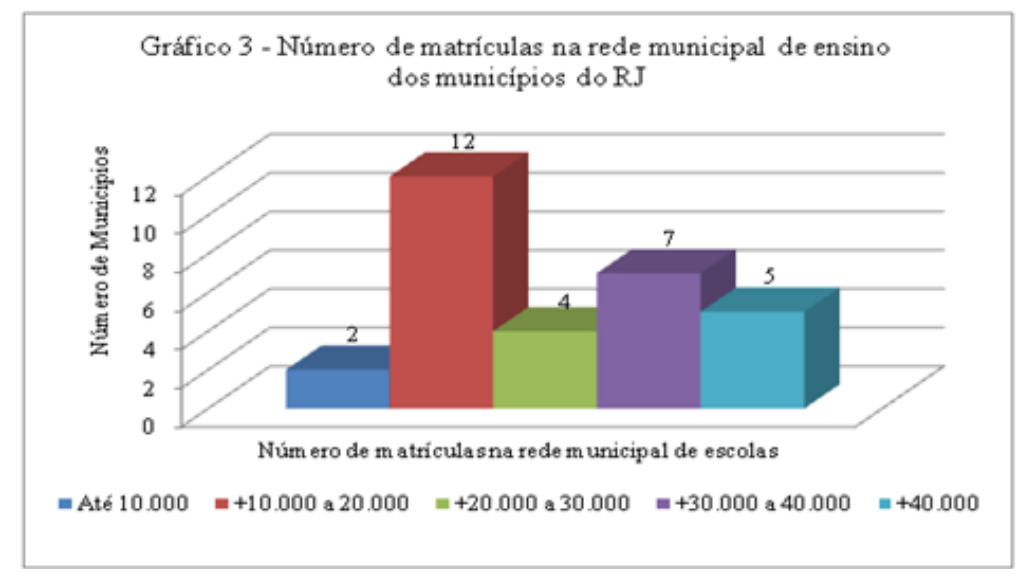

Fonte: INEPDATA-Ensino regular, 2013.

Contudo, para uma visão mais detalhada, no gráfico 4 tem-se a distribuição dos municípios de acordo com a quantidade de escolas que apresentam baixa complexidade de gestão (níveis 1 e 2) ${ }^{1}$. Em 15 dos municípios estudados, mais de

1 Nível 1 - Escolas com menos de 50 matrículas, com um único turno, uma única etapa de ensino e têm a Educação Infantil ou os Anos Iniciais como etapa mais elevada.

Nível 2 - Escolas entre 50 e 300 matrículas, com 2 turnos, até 2 etapas de ensino e têm a Educação Infantil ou os Anos Iniciais como etapa mais elevada. (INEP-ICG, 2014) 
60\% de suas escolas estão nos níveis 1 e 2 de gestão. Por outro lado, 10 municípios têm redes onde até $50 \%$ de suas escolas se encontram em níveis mais complexos de gestão.

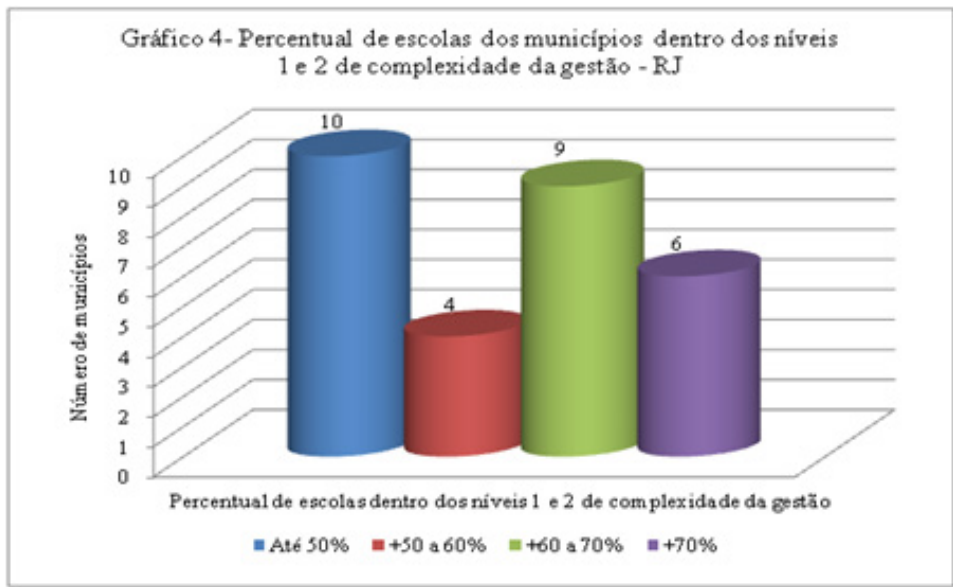

Fonte: INEP - Indicador de complexidade de gestão da escola (ICG), Educação Básica, 2014.

O gráfico 5 apresenta os municípios com escolas entre os níveis 5 e $6^{2}$, consideradas de alta complexidade de gestão interna. Nesses níveis, temos 13 municípios $^{3}$, além do Estado do Rio de Janeiro, onde mais de 15\% de suas escolas se encontra dentro dessa estrutura de organização, o que indica grandes exigências em termos de administração e apoio na composição da equipe de gestão.

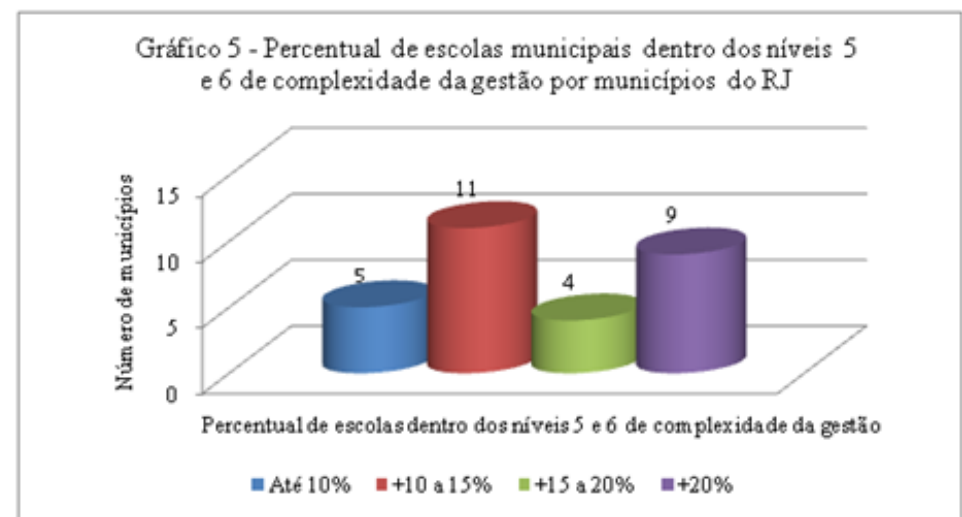

Fonte: INEP - Indicador de complexidade de gestão da escola - ICG, Educação Básica, 2014.

2 Nível 5 - Escolas entre 150 e 1000 matrículas, 3 turnos, 2 ou 3 etapas de ensino e EJA como etapa mais elevada.

Nível 6 - Escolas com mais de 500 matrículas, 3 turnos, 4 ou mais etapas de ensino e apresentam a EJA como etapa mais elevada. (INEP-ICG, 2014)

3 Os municípios são: Angra, Belford Roxo, Duque de Caxias, Itaboraí, Itaguaí, Itaperuna, Macaé, Mesquita, Nilópolis, Nova Friburgo, Nova Iguaçu, Rio das Ostras e São Gonçalo. 
Com esse levantamento estatístico, ainda que de modo mais geral, foi possível realizar um mapeamento inicial dos graus de complexidade de gestão dos sistemas de ensino e das escolas, identificando potenciais municípios e escolas que demandariam uma gestão mais elaborada e respectivas equipes, como, no caso, de uma coordenação pedagógica.

\section{O LUGAR DO COORDENADOR PEDAGÓGICO NOS SISTEMAS DE ENSINO DO RIO DE JANEIRO}

De modo a mensurar o espaço e a relevância da função de coordenação pedagógica nos sistemas de ensino do Rio de Janeiro, foram levantados, dentre os 29 municípios selecionados mais o Estado do Rio de Janeiro, os editais abertos para seleção de coordenadores pedagógicos, no período de 2006 a 2012, por meio de publicações em diários oficiais, sites dos municípios e de instituições que tradicionalmente realizam concursos públicos no Estado do Rio de Janeiro.

Do conjunto de unidades administrativas analisadas, em apenas cinco municípios não foram encontrados editais de concurso para seleção de coordenadores pedagógicos: Duque de Caxias, Magé, Nova Iguaçu, Petrópolis e Teresópolis ${ }^{4}$. Ao todo, foram identificados 31 editais lançados no período estudado, sendo que alguns municípios abriram mais de um edital no período analisado. Aqueles com maior número de editais lançados foram Itaperuna e Resende, com três editais. Já Nilópolis, Rio das Ostras, Volta Redonda e o Estado do Rio de Janeiro ${ }^{5}$ abriram dois editais no período estudado e os demais, apenas um. Outro aspecto interessante de se registrar foi a maior concentração de editais especialmente nos anos de 2011 e 2012. Se formos observar nos anos que se seguiram ao lançamento de programas federais voltados para a formação de gestores e coordenadores pedagógicos no Estado e nos municípios (2009 a 2012), é nítido o crescimento no número de editais. De 2006 a 2009, temos um total de 11 editais; nos três anos seguintes, de 2010 a 2012, esse número praticamente dobrou, com 20 editais. Ao que parece, estamos vivendo nas redes municipais de ensino do Rio de Janeiro e no Estado um movimento de ampliação das contratações de pedagogos como coordenadores pedagógicos (gráfico 6).

\footnotetext{
4 Vale observar que tais municípios abriram concurso no período estudado para a função de Pedagogo, mas sem especificar se sua atuação seria junto às escolas; portanto, não foram considerados nesse momento da pesquisa.

5 Vale observar que o Estado do Rio de Janeiro abriu editais internos à rede, para que professores já concursados pudessem exercer a função de coordenação pedagógica, pela qual receberiam uma gratificação.
} 


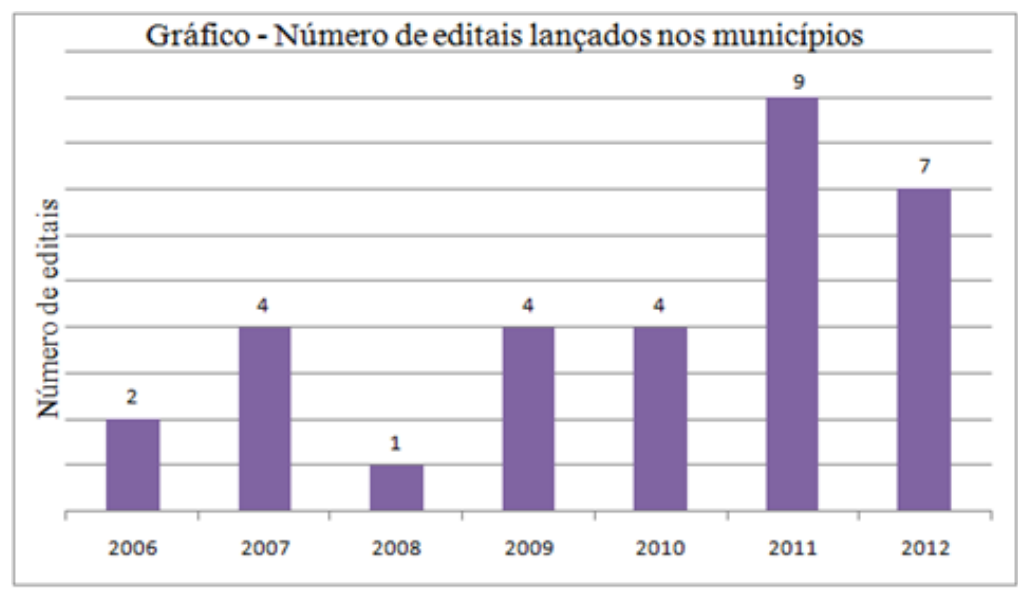

A nomenclatura utilizada para a função de coordenador pedagógico também variou entre os municípios, motivo pelo qual optamos por ampliar, em um primeiro momento, o escopo de busca nos editais, incorporando também concursos abertos para orientação educacional e supervisão, no sentido de identificar possíveis interseções entre essas funções. Dentre as denominações utilizadas para atribuições no âmbito da gestão da educação, seja na escola ou na rede de ensino, encontramos as seguintes: coordenador pedagógico; orientador pedagógico; professor orientador pedagógico; pedagogo; orientador educacional, professor orientador educacional, supervisor, supervisor educacional, inspetor escolar externo. Para efeito desse estudo, foram contabilizadas apenas os editais e vagas atribuídos às quatro primeiras funções acima listadas.

O termo mais utilizado foi 'orientador pedagógico', presente em editais de 15 municípios; ‘coordenador pedagógico' foi utilizado especialmente no Estado e no município do Rio de Janeiro e em Itaboraí; 'professor coordenador pedagógico’ em São Gonçalo e Nilópolis e o termo mais amplo, 'pedagogo', em Campos, Itaperuna, Niterói e Nova Friburgo. Em termos das vagas abertas por meio de editais, tivemos um total de 379 nos municípios estudados e 1.499 no Estado do Rio de Janeiro.

Com relação à carga horária definida para o exercício da função, na grande maioria dos editais ela se situa entre 16 a 25 horas (caso de 26 editais). $\mathrm{Na}$ faixa que vai de mais de 25 a 40 horas, estão os editais do Estado do Rio de Janeiro e, dentre estes, os que utilizam a nomenclatura 'pedagogo', oito editais. Vale observar, contudo, que, na grande maioria dos casos, o coordenador pedagógico não tem dedicação exclusiva para o exercício dessa função na escola, pois mantém sua atividade de docência, mesmo quando recebe gratificação para atuar como coordenador pedagógico. Ou seja, esse levantamento inicial de editais indica 
que ainda são poucos os concursos abertos para o exercício integral da função, prevalecendo, em termos da organização e gestão interna das escolas, a opção por articular a função de especialista em educação com o exercício da docência.

Quanto aos requisitos para os candidatos aos editais dos concursos de coordenador pedagógico, todos eles, desde 2006 até os mais recentes, exigiram a formação de nível superior e, mais especificamente, em Pedagogia; este último, com exceção de dois municípios (Japeri e Niterói). Contudo, o município de Japeri foi o único que exigiu como requisito mínimo apenas o ensino superior sem especificar qualquer relação com a área da educação. Niterói demandou, além do ensino superior, também uma habilitação na área da educação, indicando a relevância atribuída a uma formação específica, ainda que não a de pedagogo. Reforça essa posição o fato de 25 editais exigirem, além do ensino superior e do curso de Pedagogia, uma habilitação em orientação pedagógica ou uma pósgraduação na mesma área. Tal aspecto vai ao encontro do que já vinha sendo ressaltado pelas pesquisas na área, ao apontarem a necessidade de uma valorização da formação especializada e em pedagogia para o pleno e efetivo exercício das atribuições de uma coordenação pedagógica, dentre outros itens.

Vale notar, ainda, que os editais, além de exigirem a formação em Pedagogia e uma habilitação e/ou pós-graduação na área, também têm como requisito a experiência enquanto docente na educação básica. Tal exigência reforça o quadro observado anteriormente na distribuição da carga horária do coordenador pedagógico e ressalta um pouco mais o perfil de profissional que se almeja. Ou seja, além dos requisitos indicarem uma valorização da profissionalização e especialização, também reforçam, por outro lado, a visão de que esse especialista deve atuar de modo articulado com a docência, seja concomitantemente ou como experiência prévia com o exercício da função de coordenador pedagógico.

\section{CONSIDERAÇÕES}

Tanto em âmbito nacional quanto localmente no Rio de Janeiro, observase a formulação de políticas públicas voltadas para a gestão interna das escolas, das quais se desdobram uma série de questões. Neste artigo, privilegiou-se a análise da complexidade dos desafios da gestão das escolas nos sistemas de ensino do Rio de Janeiro e o lugar ocupado pela coordenação pedagógica enquanto mediadora dessa gestão nas escolas.

A partir dos levantamentos estatísticos realizados, foi possível organizar um primeiro mapeamento dos graus de complexidade da gestão das escolas, classificando-se os respectivos sistemas de ensino municipais e suas unidades escolares a partir de indicadores como número de matrículas, número de escolas, 
turnos, níveis e modalidades de ensino ofertadas. Contudo, tais dados, ainda que úteis para uma visão mais geral dos sistemas e das escolas, precisariam ser mais detalhados e aprofundados, com informações sobre o número de turmas das escolas e o tamanho da equipe de gestão destas, por exemplo.

No que diz respeito à relevância da coordenação pedagógica nas escolas das redes de ensino do Rio de Janeiro, foi possível perceber um crescimento na demanda por essa função no período analisado. Também se observou significativa mudança no perfil e na qualificação exigidas desse profissional em relação ao que vinha sendo apontado pela literatura na área, com o predomínio da exigência de uma formação específica na área de Pedagogia ou de especialização em coordenação pedagógica. Tal fato pode levar à superação de algumas dificuldades que vinham sendo apontadas pelos estudos na área, como a dedicação, de forma mais efetiva, à formação e educação continuada dos docentes nas escolas.

Vale ressaltar que, além da especialização, foi exigida também certa experiência docente, indicando um distanciamento da antiga concepção tecnicista de um especialista em educação dissociado do exercício da docência. Contudo, essa opção também acabou por reduzir a carga horária do coordenador pedagógico no exercício dessa função específica, fazendo com que tenha de acumular várias atividades.

Por fim, foram percebidos indícios de um redimensionamento das tradicionais formas de ingresso do coordenador pedagógico a sua função nas escolas. Todos esses aspectos indicam um fortalecimento do lugar desse profissional na gestão escolar, mas que ainda precisa ser aprofundado, particularmente no que diz respeito à função específica que lhe vem sendo atribuída pelos sistemas de ensino e suas concepções de gestão e o que efetivamente se tem realizado nas escolas, dimensões que serão objeto de investigação na segunda etapa de nossa pesquisa.

\section{REFERÊNCIAS}

ADRIÃO, T.; CAMARGO, R.B. A gestão democrática na constituição federal de 1988. In: OLIVEIRA, R.P.; ADRIÃO, T. (orgs.) Gestão, financiamento e direito à educação. $3^{\text {a }}$.ed. São Paulo: Xamã, 2007. p. 63-71.

ALBERNAZ, A.; FERREIRA, F.; FRANCO, C. Qualidade e equidade no ensino fundamental brasileiro. Pesquisa e Planejamento Econômico. Vol.32, no.3, p.45-59,dez, 2002. 
ALMEIDA, L.R.; PLACCO, V.M. (orgs.) O coordenador pedagógico e o espaço de mudança. SP: Loyola, 2001.

ALVEZ, M.T.G; BONAMINO, A.; FRANCO, C. Qualidade do ensino fundamental: políticas, suas possibilidades, seus limites. Educação \& Sociedade, Campinas. CEDES/UNICAMP, vol.28, n.100, pp.989-1014, 2007.

BLANCO, R. Eficácia escolar y factores associados: en America Latina y el Caribe. Santiago, LLECE/OREALC/UNESCO, 2008.

BONAMINO, A.; LIMA, N.C.M. Aspectos da gestão escolar e seus efeitos no desempenho dos alunos nos anos iniciais do ensino fundamental. In: MARTINS, A.M. et al.(orgs.) Políticas e gestão da educação: desafios em tempos de mudança. Campinas, SP: Ed.Associados,p.92-117,2013.

BROOKE, N.; SOARES, F. Pesquisa em eficácia escolar: origem e trajetórias. Belo Horizonte, Ed.UFMG, 2008.

BRUNO, E.B., ALMEIDA, L.R.; CRISTOV, L.H.S. (orgs.) O coordenador pedagógico e a formação docente.SP: Loyola, 2000.

CRISTOV, L.H.S. Intenções e problemas em práticas de coordenação pedagógica. In: ALMEIDA,L.R.; PLACCO,V.M. (orgs.) O coordenador pedagógico e o espaço de mudança. São Paulo: Loyola, p.35-44, 2001.

CRISTOV, L.H.S. Teoria e prática: enriquecimento da própria experiência. In: Guimarães, A.A. et al. O coordenador pedagógico e a educação continuada. 11ª . ed. São Paulo: Loyola, p.31-34, 2008.

FERNANDES, M. J. S. O professor coordenador e a fragilidade da carreira docente. Estudos em Avaliação Educacional, v. 20, p. 411-424, 2009.

FERREIRA, N.S.; AGUIAR, M.A. (orgs.) Para onde vão a orientação e supervisão educacional? Campinas, SP: Papirus, 2002.

FRANCO et al. Qualidade e equidade em educação: reconsiderando o significado de fatores intraescolares. Ensaio, Rio de Janeiro, vol.15, n.55, p.277-298, 2007. 
FUSARI, J. C. Formação contínua de educadores. 1997. 200 f. Tese (Doutorado em Educação) - Universidade de São Paulo, São Paulo, 1997.

GUIMARÃES, A.A. et al. O coordenador pedagógico e a educação continuada. São Paulo: Loyola, 2008.

IBGE. Censo demográfico. 2010.

INEP. INEPDATA, Ensino regular. Brasília, 2013.

INEP. ICG - Índice de complexidade de gestão. Educação básica. Brasília, 2014.

LIBÂNEO, J.C. Educação escolar: políticas, estrutura e organização. São Paulo: Cortez, 2005.

LIMA, L. A escola como organização educativa: uma abordagem sociológica. $2^{\text {a }}$ ed., São Paulo: Cortez, 2003.livro... (189pgs.)

MELO, M.A. Estado, governo e políticas públicas. In: MICELI, S. (org.) O que ler na ciência social brasileira (1970-1995): ciência política. SP/Brasília, p.5999, 1999.

OLIVEIRA, J. Um estudo sobre o coordenador pedagógico: sua identidade, seu trabalho e formação continuada no cotidiano escolar. 2009. 223p. Dissertação (Mestrado em Educação) - Pontifícia Universidade Católica do Rio de Janeiro, Rio de Janeiro, 2009.

OLIVEIRA, R.P. Da universalização do ensino fundamental ao desafio da qualidade: uma análise histórica. Educação \& Sociedade, Campinas, CEDES/ UNICAMP, vol.28, nº.100, pp.661-690, 2007.

OLIVEIRA, R.P. de; ARAÚJO, G.C.de. Qualidade do ensino: uma nova dimensão da luta pelo direito à educação. Revista Brasileira de Educação, Rio de Janeiro, n.28, p.5-23, 2005.

PARO, V.H. O princípio da gestão escolar democrática no contexto da LDB. In: OLIVEIRA, R.P.; ADRIÃO, T. (orgs.) Gestão, financiamento e direito à educação. $3^{\mathrm{a}} \mathrm{ed}$. São Paulo: Xamã, 2007. p. 73-81. 
PLACCO, V.M.N.S.; ALMEIDA, L.R. (orgs.). O coordenador pedagógico no espaço escolar: articulador, formador e transformador. São Paulo: Ed. Loyola, 2015.

PLACCO, V. M. N. S.; ALMEIDA, L. R.; SOUZA, V. L. T. (coord.). O Coordenador pedagógico e a formação de professores: intenções, tensões e contradições. (Relatório de pesquisa desenvolvida pela Fundação Carlos Chagas por encomenda da Fundação Victor Civita). São Paulo: FVC, 2011.

ROMANELLI, O. Histórica da educação no Brasil. 26ª ed., Petrópolis: Vozes, 2011.

SANTOS, L.L.; OLIVEIRA, N.H. O coordenador pedagógico no contexto da gestão democrática da escola. XXIII Simpósio ANPAE. Porto Alegre-RS:, 2007.

SOARES, J.F; ANDRADE, R.J. Nível socioeconômico, qualidade e equidade das escolas de Belo Horizonte. Ensaio, vol.14, n.50, p.107-126, jan-mar, 2006.

SOUZA, C. "Estado de campo" da pesquisa em políticas públicas no Brasil. RBCS, vol.18, no.15, p.15-20, 2003.

TAMBERLINI, A. R. M. B. Os Ginásios vocacionais: a dimensão política de um projeto pedagógico transformador. São Paulo: Annablume, 2001.

TORRES,S.R. Reuniões pedagógicas: espaço de encontro entre coordenadores pedagógicos e professores ou exigência burocrática? In: ALMEIDA, L.R.; PLACCO,V.M.(orgs.) O coordenador pedagógico e o espaço de mudança.

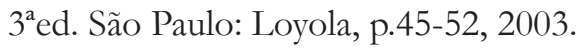

SABRINA MOEHLECKE é Socióloga, doutora em educação pela USP, Professora Associada da Faculdade de Educação da UFRJ e pesquisadora do GESED Grupo de Estudos e Pesquisas dos Sistemas Educacionais da UFRJ. E-mail: sabrina.moehlecke@gmail.com

Recebido em setembro de 2016 Aprovado em outubro de 2016 